Check for updates

Cite this: RSC Adv., 2019, 9, 22749

Received 4th June 2019

Accepted 10th July 2019

DOI: $10.1039 / c 9 r a 04216 d$

rsc.li/rsc-advances

\section{One-pot synthesis of amides via the oxidative amidation of aldehydes and amines catalyzed by a copper-MOF $\dagger$}

\author{
Samira Jamalifard, Javad Mokhtari (iD * and Zohreh Mirjafary
}

An efficient method for the oxidative amidation of aldehydes with primary aromatic and aliphatic amines has been developed for the synthesis of a wide variety of amides using inexpensive $\mathrm{Cu}_{2}(\mathrm{BDC})_{2} \mathrm{DABCO}(\mathrm{Cu}$ metal-organic framework [MOF]) as a recyclable heterogeneous catalyst, and $\mathrm{N}$-chlorosuccinimide and aqueous tert-butyl hydroperoxide as oxidants in acetonitrile. This amidation reaction is operationally straightforward and provides secondary amides in good yields in most cases, utilizing inexpensive and readily available reagents under mild conditions.

\section{Introduction}

Amide-bond formation is one of the most important organic reactions, and is essential in the synthesis of pharmaceuticals, natural products and polymers such as peptides, bortezomib (an anticancer drug) and nylon 66, for example. ${ }^{1}$ Indeed, more than $25 \%$ of drugs contain at least one amide group. ${ }^{2}$ Routine amide synthesis from amines and carboxylic acids involves the use of coupling agents including carbodiimides, carbonyldiimidazole, hydroxybenzotriazoles and 2-(1H-benzotriazol-1yl)-1,1,3,3-tetramethyluronium hexafluorophosphate (TBTU), for example. ${ }^{3}$ Alternatively, amides are often produced from the reaction of an amine with activated carboxylic acid derivatives. ${ }^{4}$ These methods have several drawbacks, such as poor atom efficiency, use of hazardous and expensive reagents and generation of waste products leading to environmental problems. To address these challenges, novel routes to amide-bond formation have been developed over recent years, including the Staudinger reaction, ${ }^{5}$ an acid-promoted Schmidt reaction that forms an amide from an alkyl azide and a ketone, ${ }^{6}$ catalytic acylation of amines with carboxylic acid, ${ }^{7}$ aerobic oxidative coupling of alcohols and amines, ${ }^{8}$ hydroamination of alkynes, ${ }^{9}$ amino carbonylation of haloarenes ${ }^{\mathbf{1 0}}$ and oxidative amidation of aldehydes. ${ }^{11-21}$ Among these, oxidative amidation of aldehydes is synthetically useful, as not only are both starting materials readily available, but the process is atomically economical and environmentally benign.

Oxidative amidation of aldehydes with amines was first reported by Nakagawa and co-workers ${ }^{11}$ using stoichiometric amounts of nickel peroxide. Subsequently, several research

Department of Chemistry, Science and Research Branch, Islamic Azad University, P. O. box 14515/775, Tehran, Iran. E-mail: j.mokhtari@srbiau.ac.ir

† Electronic supplementary information (ESI) available. See DOI: 10.1039/c9ra04216d groups have developed new methods for the direct conversion of amides from aldehydes using iodine, ${ }^{12} \mathrm{~N}$-bromosuccinimide (NBS), ${ }^{13}$ manganese oxide $^{\mathbf{1 4}}$ and tert-butylhydroperoxide $(\mathrm{TBHP})^{16}$ as oxidizing agents. In addition, catalytic methods using copper, ${ }^{22}$ copper/silver, ${ }^{18}$ transition metals (Pd, Rh and $\mathrm{Ru})^{19}$ and lanthanides ${ }^{20}$ have also been reported. These pioneering works provide efficient and environmentally advantageous methods for amide formation. However, in some cases, the reactions require hazardous and expensive dual catalysts, and in most cases, separation of homogenous catalysts such as $\mathrm{CuSO}_{4}$ and $\mathrm{Cu}(\mathrm{OAc})_{2}$ is problematic and the catalysts are not recyclable. ${ }^{22 b, c}$ Hence, the search for a less costly, greener, heterogeneous and simpler catalyst system remains a challenge.

As part of our ongoing work to develop metal-organic frameworks (MOFs) as efficient heterogeneous, green and recyclable catalysts in organic synthesis, ${ }^{23}$ we report herein the improved oxidative amidation of aldehydes $\mathbf{1}$ with a primary amine 2 for the synthesis of secondary amides 3, using inexpensive and a readily available $\mathrm{Cu}-\mathrm{MOF}, \mathrm{Cu}_{2}(\mathrm{BDC})_{2} \mathrm{DABCO}$, as the recyclable catalyst, and $N$-chlorosuccinimide (NCS) and tertbutyl hydroperoxide (TBHP) as the oxidants (Scheme 1).

\section{Experimental section}

\section{Materials and methods}

All chemicals were purchased from commercial sources and used without further purification. $\mathrm{Cu}_{2}(\mathrm{BDC})_{2}(\mathrm{DABCO})$ was synthesized according to our previously reported procedure. ${ }^{23 a}$ All reactions were monitored by thin-layer chromatography (TLC) using plates coated with Merck 60 HF254 silica under ultraviolet (UV) light. Infrared (IR) spectra were recorded using a Shimadzu 8400s Fourier-transform (FTIR) spectrometer. ${ }^{1} \mathrm{H}$ nuclear magnetic resonance (NMR) and ${ }^{13} \mathrm{C}-\mathrm{NMR}$ spectra were recorded using a BRUKER DRX 500-AVANCE FT-NMR instrument $\left(\mathrm{CDCl}_{3}\right.$ solution) at 500 and $125 \mathrm{MHz}$, respectively. 


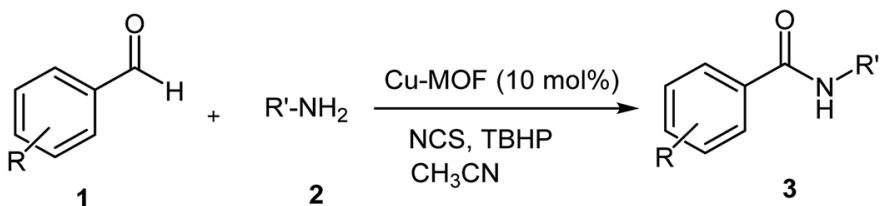

Scheme 1 Oxidative amidation of aldehydes with amine catalyzed by $\mathrm{Cu}_{2}(\mathrm{BDC})_{2} \mathrm{DABCO}(\mathrm{Cu}-\mathrm{MOF})$.

Scanning electron microscope (SEM) images were captured with a ZEISS scanning electron microscope at $30 \mathrm{kV}$ with gold coating.

\section{Synthesis of amides via the oxidation amidation of aldehydes and amines catalyzed by $\mathrm{Cu}_{2}(\mathrm{BDC})_{2}(\mathrm{DABCO})$}

To a solution of amine $(1 \mathrm{mmol})$ in $\mathrm{CH}_{3} \mathrm{CN}(5 \mathrm{ml})$, NCS was added $(1 \mathrm{mmol})$ and the reaction mixture was stirred for $1 \mathrm{~h}$ at room temperature. Then, aldehyde $(1 \mathrm{mmol}), \mathrm{Cu}_{2}(\mathrm{BDC})_{2} \mathrm{DABCO}$ $(10 \% \mathrm{~mol})$ and TBHP $70 \%(1 \mathrm{mmol})$ were added, and the reaction temperature was increased up to $65{ }^{\circ} \mathrm{C}$ and the reaction mixture was allowed to stir for $2 \mathrm{~h}$. The reaction progress was monitored by TLC. After reaction completion, the catalyst was filtered and the filtrate was evaporated under reduced pressure, before the residue was purified using silica gel column chromatography (hexane/ethyl acetate $[4: 1]$ ).

\section{Synthesis of $N$-benzylbenzamide ( $2 \mathrm{~g}$ scale)}

To a solution of benzylamine $(1.4 \mathrm{ml}, 12.8 \mathrm{mmol})$ in $\mathrm{CH}_{3} \mathrm{CN}(20$ $\mathrm{ml})$, NCS $(1.71 \mathrm{~g}, 12.8 \mathrm{mmol})$ was added and the reaction mixture was stirred for $1 \mathrm{~h}$ at room temperature. Then, benzaldehyde ( $1.3 \mathrm{ml}, 12.8 \mathrm{mmol}), \mathrm{Cu}_{2}(\mathrm{BDC})_{2} \mathrm{DABCO}(10 \% \mathrm{~mol})$ and TBHP $70 \%$ (1.76 ml, $12.8 \mathrm{mmol})$ were added, and the reaction temperature was increased up to $65^{\circ} \mathrm{C}$ and the reaction mixture was allowed to stir for $2 \mathrm{~h}$. The reaction progress was monitored by TLC. After reaction completion, the catalyst was filtered and the filtrate was evaporated under reduced pressure, before the residue was purified using silica gel column chromatography (hexane/ethyl acetate $[4: 1])$ to yield $2.01 \mathrm{~g}$ of $3 \mathrm{a}(74 \%)$.

\section{Selected spectral data}

$N$-Benzylbenzamide, white solid; $160 \mathrm{mg}$, yield: 75\%; mp: 104$106{ }^{\circ} \mathrm{C} .{ }^{1} \mathrm{H}$ NMR $\left(500 \mathrm{MHz}, \mathrm{CDCl}_{3}\right): \delta 7.79(\mathrm{~d}, J=7.1 \mathrm{~Hz}, 2 \mathrm{H})$, $7.48-7.51(\mathrm{t}, J=7.1 \mathrm{~Hz}, 1 \mathrm{H}), 7.41-7.44(\mathrm{~m}, 2 \mathrm{H}), 7.32-7.36(\mathrm{~m}$, $4 \mathrm{H}), 7.26-7.31(\mathrm{~m}, 1 \mathrm{H}), 6.44$ (brs, $1 \mathrm{H}), 4.65(\mathrm{~d}, J=5.5 \mathrm{~Hz}, 2 \mathrm{H})$. ${ }^{13} \mathrm{C} \mathrm{NMR}\left(125 \mathrm{MHz}, \mathrm{CDCl}_{3}\right): \delta 167.5,138.2,134.5,131.7,128.9$, 128.7, 128.1, 127.7, 127.1, 44.2.

\section{Results and discussion}

$\mathrm{Cu}_{2}(\mathrm{BDC})_{2} \mathrm{DABCO}(\mathrm{Cu}-\mathrm{MOF})$ catalysts were prepared and characterized using our previously reported method. ${ }^{23 a}$ First, a model reaction of benzaldehyde 1a and benzyl amine in the presence of TBHP to form $N$-benzylbenzamide was chosen to identify the catalytic system. Different amounts of Cu-MOF were screened at room temperature under reflux conditions, but unfortunately, only a trace of product was observed (Table 1, entries 1-4). In another attempt, benzylamine and NCS were first reacted together in acetonitrile at room temperature for $1 \mathrm{~h}$ followed by the addition of $5 \mathrm{~mol} \%$ of the catalyst and stoichiometric amounts of benzaldehyde and TBHP (1.0 equiv.) at room temperature. In this case, we found that benzaldehyde was converted to $N$-benzylbenzamide, $3 \mathrm{a}$, in only $35 \%$ yield after $24 \mathrm{~h}$ (entry 5). Increasing the reaction temperature from 25 to $65{ }^{\circ} \mathrm{C}$ resulted in a significant increase in the yield of up to $75 \%$ after $2 \mathrm{~h}$ (entry 6 ). With 1 mol\% catalyst loading, the yield of the amide decreased slightly to $60 \%$ (entry 7 ), while use of $10 \mathrm{~mol} \%$ loading did not significantly affect the yield of the reaction (Table 1, entry 8).

The effect of the solvents was also investigated, and benzaldehyde and benzylamine were subjected to the same reaction conditions with two other solvents, dimethylformamide (DMF) and tetrahydrofuran (THF). It was found that acetonitrile was the best solvent for this reaction (entries 9-10), possibly due to the dependence of the proton-transfer-mediated electron transfer on the solvent type. The donor number of the solvent decreases in the order of DMF (26.6) $>$ THF (20.0) $>\mathrm{CH}_{3} \mathrm{CN}$ (14.8), and as a result, the yield of products increased

Table 1 Optimization of the reaction conditions for amide bond formation from aldehydes ${ }^{a}$

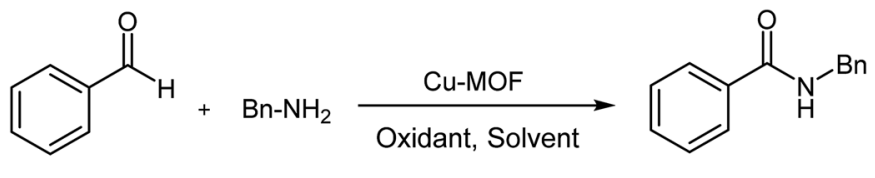

$1 \mathrm{a}$ 2a $3 a$

\begin{tabular}{lcllll}
\hline Entry & $\begin{array}{l}\text { Catalyst Cu-MOF } \\
(\mathrm{mol} \%)\end{array}$ & Oxidant & Solvent & $T\left({ }^{\circ} \mathrm{C}\right)$ & Yield (\%) \\
\hline 1 & 5 & TBHP & $\mathrm{CH}_{3} \mathrm{CN}$ & 25 & Trace \\
2 & 10 & TBHP & $\mathrm{CH}_{3} \mathrm{CN}$ & 25 & Trace \\
3 & 20 & TBHP & $\mathrm{CH}_{3} \mathrm{CN}$ & 25 & Trace \\
4 & 20 & TBHP & $\mathrm{CH}_{3} \mathrm{CN}$ & 80 & 10 \\
5 & 5 & NCS/TBHP & $\mathrm{CH}_{3} \mathrm{CN}$ & 25 & 35 \\
6 & 5 & NCS/TBHP & $\mathrm{CH}_{3} \mathrm{CN}$ & 65 & 75 \\
7 & 1 & NCS/TBHP & $\mathrm{CH}_{3} \mathrm{CN}$ & 65 & 60 \\
8 & 10 & NCS/TBHP & $\mathrm{CH}_{3} \mathrm{CN}$ & 65 & 76 \\
9 & 5 & NCS/TBHP & $\mathrm{DMF}^{2}$ & 80 & 51 \\
10 & 5 & NCS/TBHP & $\mathrm{THF}$ & 65 & 62 \\
11 & 5 & NCS & $\mathrm{CH}_{3} \mathrm{CN}$ & 65 & Trace \\
12 & - & NCS/TBHP & $\mathrm{CH}_{3} \mathrm{CN}$ & 65 & -
\end{tabular}

${ }^{a}$ Reaction conditions: benzaldehyde $(1 \mathrm{mmol})$, benzylamine $(1 \mathrm{mmol})$, oxidant $(1.0 \mathrm{mmol})$, solvent $(5 \mathrm{ml})$, time: $2 \mathrm{~h}$. 
Table 2 Cu-MOF catalyzed synthesis of secondary amides from aldehydes and primary amines ${ }^{a}$

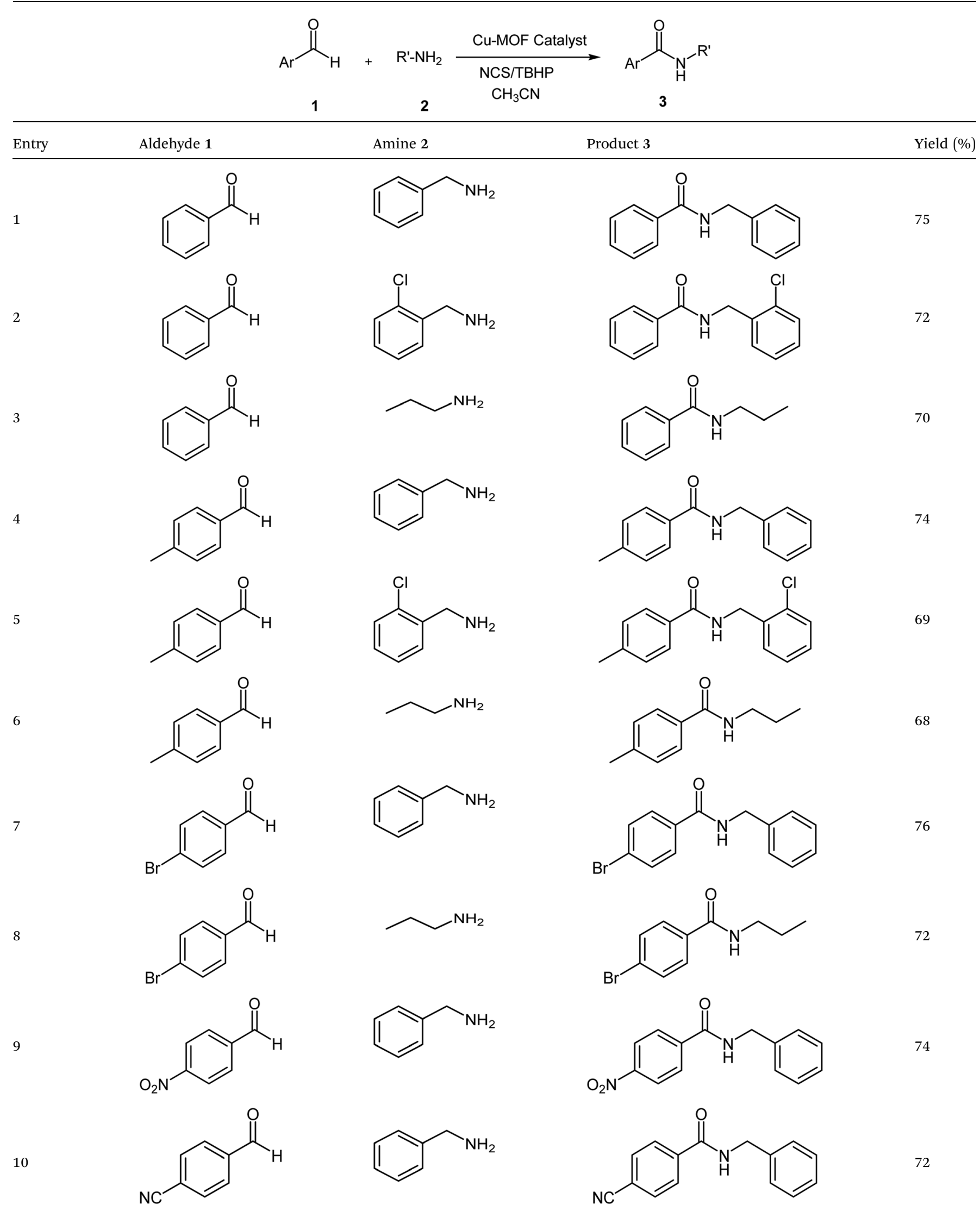

\footnotetext{
${ }^{a}$ Reaction conditions: 1 (1.0 equiv.), 2 (1.0 equiv.), NCS (1.0 equiv.), TBHP (1.0 equiv.), $\mathrm{Cu}-\mathrm{MOF}(10 \mathrm{~mol} \%)$ in $\mathrm{CH}_{3} \mathrm{CN}(5 \mathrm{ml})$ at $65{ }^{\circ} \mathrm{C}$ for 2 h.
} 
Table 3 Recovery and reuse of Cu-MOF in the oxidative amination of aldehyde

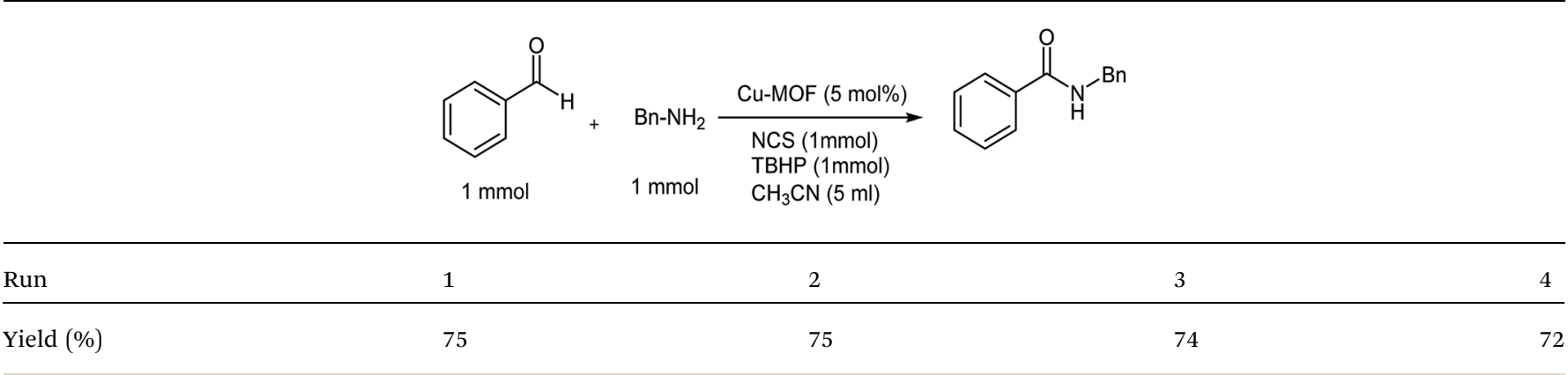

accordingly. ${ }^{24}$ Control experiments (entries 11-12) revealed that an oxidant (TBHP; entry 11) and Cu-MOF catalyst (entry 12), are both necessary for amide bond formation.

After optimization of the model reaction, and in order to understand the substrate scope of this reaction, a wide range of aromatic aldehydes and the amine were reacted under the optimized reaction conditions (Table 2). Good yields of secondary amides were obtained in most cases (3a-g). Aldehydes with electron-donating or electron-withdrawing substituents achieved good to excellent yields of secondary amides $(3 \mathbf{k}-\mathbf{p})$, indicating that the reaction is not sensitive to electronic effects. Benzyl and aliphatic amines (2a-g) were the most favored substrates, and provided good yields of the amide products.

The catalyst Cu-MOF also exhibited good recyclability and stability. For instance, the catalyst was recovered by simple filtration, washed with methanol and dried in an oven, and could be reused four times (Table 3 ). The catalyst could also be stored for a long time under an air atmosphere without any significant loss of catalytic activity.
The X-ray diffraction (XRD) pattern of $\mathrm{Cu}_{2}(\mathrm{BDC})_{2} \mathrm{DABCO}$ shows that the crystalline structure of $\mathrm{Cu}_{2}(\mathrm{BDC})_{2} \mathrm{DABCO}$ is maintained after four runs (Fig. 1). ${ }^{23}$

Based on previously reported studies, ${ }^{25}$ we considered a possible mechanism for this reaction, as shown in Scheme 2. $\mathrm{Cu}(\mathrm{II})$ oxidized TBHP in such a way that TBHP was transformed into a tert-butylperoxy radical and $\mathrm{Cu}$ (II) was also reduced to $\mathrm{Cu}(\mathrm{I})$. The tert-butylperoxy radical captured a hydrogen from benzaldehyde, thereby converting the aldehyde into a benzoyl radical, as reported by $\mathrm{Xu}$ et $a{ }^{26}{ }^{26}$ With the redox reaction, the $N$ chloramine (resulting from the reaction of benzylamine and NCS) was transformed into an amino radical, as reported as reported by Minisci. ${ }^{21,22,27}$ In the last step, the amino radical and the benzoyl radical were coupled to yield the corresponding amide products.

A comparison with other catalytic systems in the oxidative amidation of aldehydes and amines demonstrated that our present $\mathrm{Cu}-\mathrm{MOF}$ catalyst system exhibits a better catalyst performance (Table 4).

The structures of all products were elucidated from their ${ }^{1} \mathrm{H}$ NMR spectra and melting points, as described for $\mathrm{N}$ -

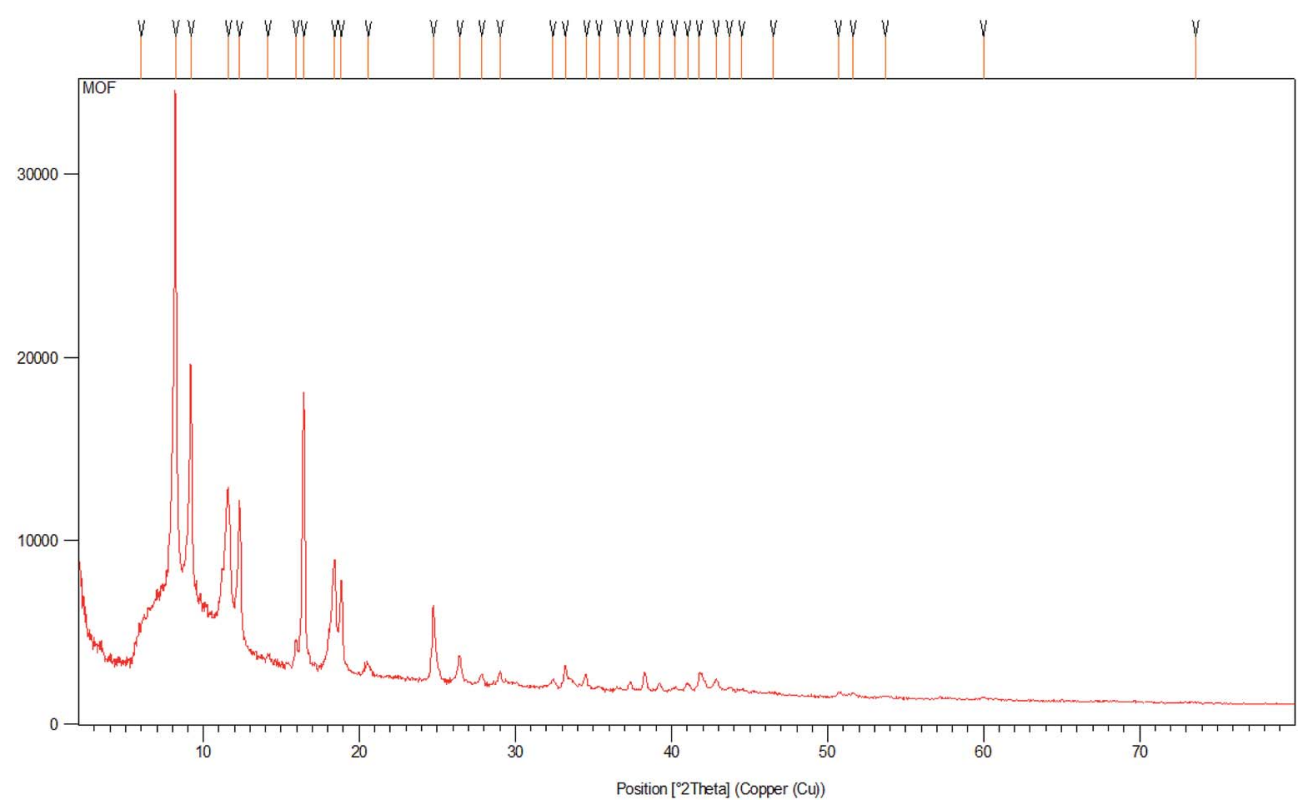

Fig. 1 XRD pattern of recycled $\mathrm{Cu}_{2}(\mathrm{BDC})_{2} \mathrm{DABCO}$. 


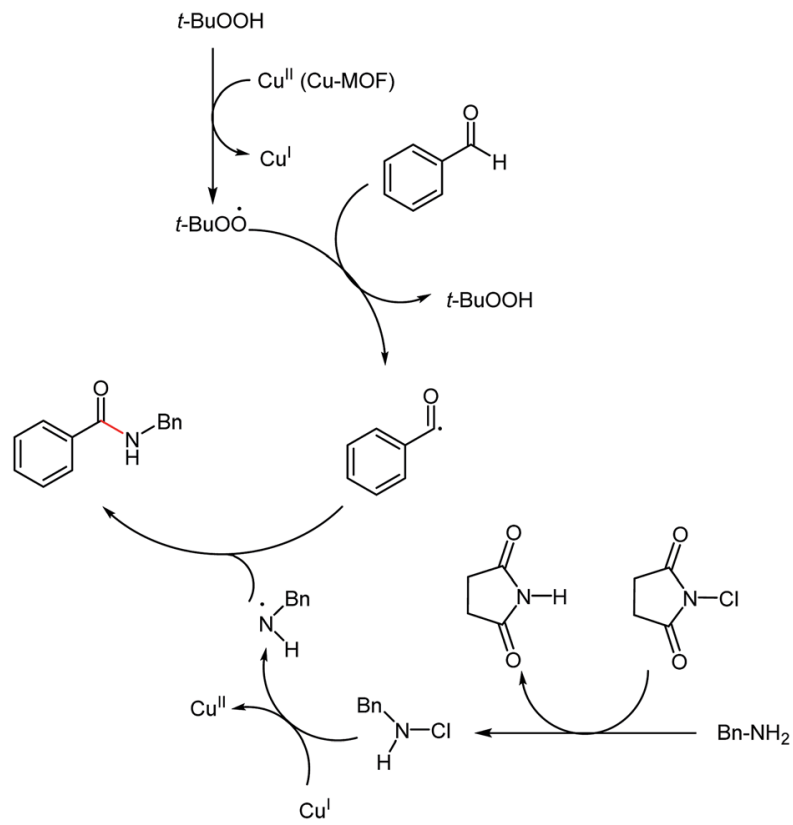

Scheme 2 Proposed mechanism for the synthesis of amides catalyzed by Cu-MOF.

Table 4 Comparison of activity for different catalytic systems in the oxidative amidation of aldehydes

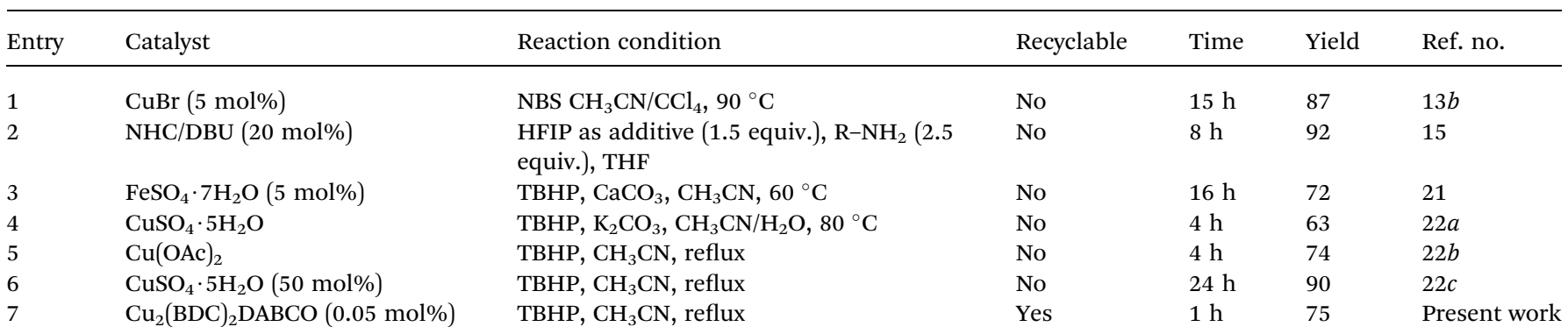

phenylbenzamide. The ${ }^{1} \mathrm{H}$-NMR spectrum of diphenyl amine showed that the aromatic protons gave rise to multiplets in the region $\delta=6.92-7.28 \mathrm{ppm}$, benzylic $\mathrm{CH}_{2}$ at $4.64 \mathrm{ppm}$ and $\mathrm{N}-\mathrm{H}$ at $6.45 \mathrm{ppm}$.

\section{Conclusion}

In conclusion, we have identified $\mathrm{Cu}-\mathrm{MOF}$ as a green and recyclable heterogeneous catalyst for the efficient oxidative amidation of aldehydes with primary amines for the synthesis of secondary amides. A different range of amines and aldehydes are applicable in this reaction. Furthermore, this novel costeffective amide formation reaction provides practical alternatives for the synthesis of amides under mild conditions. Further studies on the catalytic application MOFs are in progress and will be presented in the future.

\section{Conflicts of interest}

There are no conflicts to declare.

\section{References}

1 (a) J. W. Bode, Curr. Opin. Drug Discovery Dev., 2006, 9, 765; (b) T. Cupido, J. Tulla-Puche, J. Spengler and F. Albericio, Curr. Opin. Drug Discovery Dev., 2007, 10, 768; (c) J. M. Humphrey and A. R. Chamberlin, Chem. Rev., 1997, 97, 2243.

2 (a) E. Valeur and M. Bradley, Chem. Soc. Rev., 2009, 38, 606; (b) R. C. Larock, Comprehensive Organic Transformations, VCH, New York, 1999; (c) https:/www.fda.gov/Drugs/ DrugSafety/ucm106494.htm.

3 (a) J. M. Humphrey and A. R. Chamberlin, Chem. Rev., 1997, 97, 2243-2266; (b) P. Wipf, Reagents for High-Throughput Solid-Phase and Solution- Phase Organic Synthesis, in Handbook of Reagents for Organic Synthesis, Wiley \& Sons, New York, 2005; (c) E. Valeur and M. Bradley, Chem. Soc. Rev., 2009, 38, 606-631.

4 (a) S. Naik, G. Bhattacharjya, B. Talukdar and B. K. Patel, Eur. J. Org. Chem., 2004, 1254-1260; (b) A. Teichert, K. Jantos, K. Harms and A. Studer, Org. Lett., 2004, 6, 3477-3480; (c) 
D. M. Shendage, R. Froehlich and G. Haufe, Org. Lett., 2004, 6, 3675-3678; (d) D. A. Black and B. A. Arndtsen, Org. Lett., 2006, 8, 1991-1993; (e) A. R. Katritzky, C. Cai and S. K. Singh, J. Org. Chem., 2006, 71, 3375-3380.

5 (a) B. L. Nilson, L. L. Kiessling and R. T. Raines, Org. Lett., 2000, 2, 1939-1940; (b) F. Damakaci and P. DeShong, J. Am. Chem. Soc., 2003, 125, 4408-4409; (c) N. Shangguan, S. Katukojvala, R. Greenberg and L. J. Williams, J. Am. Chem. Soc., 2003, 125, 7754-7755; (d) R. Merkx, A. J. Brouwer, D. T. S. Rijkers and R. M. J. Liskamp, Org. Lett., 2005, 7, 1125-1128.

6 (a) R. F. Schmidt, Ber. Dtsch. Chem. Ges., 1924, 57, 704-706; (b) L. Yao and J. Aube, J. Am. Chem. Soc., 2007, 129, 27662767.

7 (a) K. Ishihara, S. Ohara and H. Yamamoto, J. Org. Chem., 1996, 61, 4196; (b) P. Tang, Org. Synth., 2005, 81, 262; (c) H. Charville, D. Jackson, G. Hodges and A. Whiting, Chem. Commun., 2010, 46, 1813; (d) C. L. Allen, R. A. Chhatwal and J. M. J. Williams, Chem. Commun., 2012, 48, 666.

8 L. Zhang, W. Wang, A. Wang, Y. Cui, X. Yang, Y. Huang, X. Liu, W. Liu, J.-Y. Son, H. Ojic and T. Zhang, Green Chem., 2013, 15, 2680-2684.

9 (a) S. Cho, E. Yoo, I. Bae and S. Chang, J. Am. Chem. Soc., 2005, 127, 16046; (b) Z.-W. Chen, H.-F. Jiang, X.-Y. Pan and Z.-J. He, Tetrahedron, 2011, 67, 5920.

10 (a) J. R. Martinelli, T. P. Clark, D. A. Watson, R. H. Munday and S. L. Buchwald, Angew. Chem., Int. Ed., 2007, 46, 8460; (b) A. Brennführer, H. Neumann and M. Beller, Angew. Chem., Int. Ed., 2009, 48, 4114; (c) T. T. Dang, Y. Zhu, S. C. Ghosh, A. Chen, C. L. L. Chai and A. M. Seayad, Chem. Commun., 2012, 48, 1805.

11 (a) K. Nakagawa, H. Inoue and K. Minami, Chem. Commun., 1966, 17; (b) K. Nakagawa, S. Mineo, S. Kawamura, M. Horikawa, T. Tokumoto and O. Mori, Synth. Commun., 1979, 9, 529.

12 J. Shie and J. Fang, J. Org. Chem., 2003, 68, 1158.

13 (a) E. I. Marks and A. Mekhalfia, Tetrahedron Lett., 1990, 31, 7237; (b) L. Wang, H. Fu, Y. Jiang and Y. Zhao, Chem.-Eur. J., 2008, 14, 10722.

14 N. W. Gilman, J. Chem. Soc. D, 1971, 733.

15 S. D. Sarkar and A. Studer, Org. Lett., 2010, 12, 1992.

16 (a) K. Ekoue-Kovi and C. Wolf, Org. Lett., 2007, 9, 3429; (b) K. Ekoue-Kovi and C. Wolf, Chem.-Eur. J., 2008, 14, 6302.

17 (a) H. U. Vora and T. Rovis, J. Am. Chem. Soc., 2007, 129, 13796; (b) J. W. Bode and S. S. Sohn, J. Am. Chem. Soc., 2007, 129, 13798.
18 W.-J. Yoo and C.-J. Li, J. Am. Chem. Soc., 2006, 128, 13064. 19 (a) Y. Tamaru, Y. Yamada and Z. Yoshida, Synthesis, 1983, 474; (b) T. Naota and S.-I. Murahashi, Synlett, 1991, 693; (c) A. Tillack, I. Rudloff and M. Beller, Eur. J. Org. Chem., 2001, 523; (d) W.-K. Chan, C.-M. Ho, M.-K. Wong and C.-M. Che, J. Am. Chem. Soc., 2006, 128, 14796; (e) Y. Suto, N. Yamagiwa and Y. Torisawa, Tetrahedron Lett., 2008, 49, 5732; (f) J. W. W. Chang and P. W. H. Chan, Angew. Chem., Int. Ed., 2008, 47, 1138; (g) S. Muthaiah, S. C. Ghosh, J.-E. Jee, C. Chen, J. Zhang and S. H. Hong, J. Org. Chem., 2010, 75, 3002.

20 (a) S. Seo and T. J. Marks, Org. Lett., 2008, 10, 317; (b) C. Qian, X. Zhang, J. Li, F. Xu, Y. Zhang and Q. Shen, Organometallics, 2009, 28, 3856; (c) J. M. Li, F. Xu, Y. Zhang and Q. Shen, J. Org. Chem., 2009, 74, 2575.

21 S. C. Ghosh, J. S. Y. Ngiam, C. L. L. Chai, A. M. Seayad, D. T. Tuan and A. Chen, Adv. Synth. Catal., 2012, 354, 1407. 22 (a) S. C. Ghosh, J. S. Y. Ngiam, A. M. Seayad, D. T. Tuan, C. L. L. Chai and A. Chen, J. Org. Chem., 2012, 77, 80078015; (b) R. Cadoni, A. Porcheddu, G. Giacomelli and L. D. Luca, Org. Lett., 2012, 14, 5014-5017; (c) J. Gu, Z. Fang, Y. Yang, Z. Yang, L. Wan, X. Li, P. Wei and K. Guo, RSC Adv., 2016, 6, 89413-89416.

23 (a) L. Panahi, M. R. Naimi-Jamal, J. Mokhtari and A. Morsali, Microporous Mesoporous Mater., 2016, 244, 208-217; (b) S. Akbari, J. Mokhtari and Z. Mirjafary, RSC Adv., 2017, 7, 40881-40886; (c) A. Khosravi, J. Mokhtari, M. R. NaimiJamal, S. Tahmasebi and L. Panahi, RSC Adv., 2017, 7, 46022-46027; (d) S. Tahmasebi, A. Khosravi, J. Mokhtari, M. R. Naimi-Jamal and L. Panahi, J. Organomet. Chem., 2017, 853, 35-41; (e) J. Mokhtari and B. A. Hassani, Inorg. Chim. Acta, 2018, 482, 726-731; (f) Z. Ahmadzadeh, J. Mokhtari and M. Rouhani, RSC Adv. , 2018, 8, 24203-24208. 24 (a) C. Reichardt and T. Welton, Solvents and Solvent Effects in Organic Chemistry, WILEY-VCH Verlag GmbH \& Co. KGaA, Weinheim, 3rd edn, 2011; (b) V. Gutmann, Electrochim. Acta, 1976, 21, 661; (c) P. Neta, R. E. Huie, P. Maruthamuthu and S. Steenken, J. Phys. Chem., 1989, 93, 7654-7659.

25 Y. Yang, J. Gu, Z. Fang, Z. Yang, P. Wei and K. Guo, RSC Adv., 2017, 7, 22797.

26 K. Xu, Y. Hu, S. Zhang, Z. Zha and Z. Wang, Chem.-Eur. J., 2012, 18, 9793.

27 F. Minisci, Synthesis, 1973, 1. 